JEL Classification: G10, G11, G12, G15, G31

Keywords: CAPM, macroeconomic factor models, asset pricing, cost of capital, Poland

\title{
Testing Multi-Factor Asset Pricing Models in the Visegrad Countries
}

Magdalena Morgese BORYS - CERGE-EI (Center for Economic Research and Graduate Education of Charles University and Economic Institute of the Academy of Sciences of the Czech Republic) (magdalena.borys@cerge-ei.cz)

\section{Abstract}

There is no consensus in the literature as to which model should be used to estimate stock returns and the cost of capital in the emerging markets. The Capital Asset Pricing Model (CAPM), which is most often used for this purpose in the developed markets, has a poor empirical record and is likely not to hold in the less developed and less liquid emerging markets. Various factor models have been proposed to overcome the shortcomings of the CAPM. This paper examines both the CAPM and macroeconomic factor models in terms of their ability to explain average stock returns using data from the Visegrad countries. We find, as expected, that the CAPM is not able to do this task. However, factor models, including factors such as the excess market return, industrial production, inflation, money, the exchange rate, exports, the commodity index, and the term structure, can in fact explain part of the variance in the Visegrad countries' stock returns.

\section{Introduction}

Emerging markets have been studied quite extensively due to the large interest of investors, who view them as an attractive alternative to investing in more developed markets. Emerging markets are typically characterized by higher returns, but also by higher volatility of stock returns as compared to the developed ones. ${ }^{1}$

However, there is no consensus in the literature as to which model should be used to explain the returns in these markets and estimate the cost of equity capital. The aim of this paper is to propose such a model for the stock markets in the Visegrad countries: the Czech Republic, Hungary, Poland, and Slovakia. More specifically, we will analyze how different models perform in explaining the variations in stock returns on the stock markets and which one of these models should be used to estimate the cost of equity capital in these markets.

The cost of equity capital is crucial information that is needed in order to assess investment opportunities and the performance of managed portfolios. The cost of equity capital is used as a discount factor when calculating the net present value (NPV) of investment projects. $^{2}$ In developed markets, the capital asset pricing model (CAPM) is commonly used by financial managers to calculate the cost of equity capital, as well as to assess the performance of managed portfolios such as mutual funds (Fama and French, 2004). The rationale behind using the cost of equity capital estimated by the CAPM is the following: since the future payoffs from an investment are

\footnotetext{
* I would like to express my gratitude to Petr Zemcik for useful comments and suggestions. I have also benefited from discussions with Evzen Kocenda and Jan Hanousek.

${ }^{1}$ This fact is well documented in the literature. See, for example, Bekaert and Harvey (1997) and Rouwenhorst (1999).
} 
risky, i.e., not certain, the rate of return used to calculate the NPV of this investment should come from a comparably risky alternative investment opportunity. A good candidate for such an alternative is investment in the stock market. In fact, Graham and Harvey (2001) report that 75.5 percent of the 392 respondents to their survey use the CAPM to estimate the cost of equity capital, which is then used to calculate the NPV of investment projects, where the cost of equity capital is used as the discount rate. Correct estimation of the cost of equity capital is key. If the estimate of the firm's beta coming from the CAPM is biased upward it may lead to the rejection of profitable investment projects, i.e., when the internal rate of return is not greater than the upward biased hurdle rate.

The CAPM, first formulated by Sharpe (1964), Lintner (1965), and Black (1972), describes the relationship between risk and expected return and is used to price risky securities. The very clear and intuitive link between the risk of an asset in relation to the risk of the overall market and the expected return on the asset is one of the main advantages of the CAPM and is key to understanding its widespread use. However, it is well documented in the literature that the CAPM fails to explain the cross section of average stock returns. While Black, Jensen, and Scholes (1972) and Fama and MacBeth (1973) find that the CAPM holds for the 1926-1968 period, more recent studies of the period from 1960 to date find otherwise. Among the first studies to report the disappearance of the simple relation between the risk of an asset and the average return as predicted by the CAPM were Reinganum (1981) and Lakonishok and Shapiro (1986). There are two possible reasons proposed in the literature for the failure of the CAPM to explain average stock returns. First, there may be a number of priced risks that a single-factor model is not able to account for properly. Second, time variation in either risk or the price of risk may cause unconditional models to fail.

Following the first line of reasoning, a number of researchers have explored alternative risk factors and proposed various multifactor models. ${ }^{3}$ Fama and French $(1993,1996)$ propose a three-factor model which includes, in addition to market returns, two factors related to the firm's size (SMB) and the firm's book value (HML). ${ }^{4}$ They believe that their SMB and HML factors proxy for unobserved common risk in

\footnotetext{
${ }^{2}$ In principle, by using the net present value, investors want to verify whether the payoff of the investment exceeds its cost. The future payoffs expected from a particular investment need to be discounted so that they can be compared to the costs of the investment that must be incurred at the present time. A good discussion of the NPV methodology can be found in Brealey and Myers (1988). In short, the simple NPV formula is as follows: $N P V=C_{0}+\frac{C_{1}}{1+r}+\frac{C_{2}}{(1+r)^{2}}+\ldots$,

where $C_{0}$ is the cash flow today (i.e., the cost of investment, a negative number), $C_{1}$ is the payoff from the investment one period ahead, and $r$ is the rate of return that investors demand for the delayed payment. This is the cost of capital.

${ }^{3}$ In addition to the ones mentioned in this section, see Breeden (1979), who developed the Consumption CAPM (CCAPM), and extensions of the CCAPM, including Campbell (1996), Cochrane (1996), Parker and Juliard (2005), Jagannathan and Wang (2005), Piazzesi, Schneider, and Tuzel (2007), and Yogo (2006).

${ }^{4}$ In order to obtain these factors the stocks need to be grouped into portfolios on the basis of the firm's size as well as the firm's book-to-market value. Their three-factor model then consists of the excess market return, the return on small stocks minus the return on big stocks (SMB), and the return on stocks with high book-to-market ratios minus the return on stocks with low book-to-market ratios (HML).
} 
portfolios. ${ }^{5}$ In addition, factors related to some macro variables have proven to be able to explain the variation in stock returns. Chen, Roll, and Ross (1986) test whether additional sources of risk such as innovations in macroeconomic variables are priced in the stock market. They find that the spread between long- and short-term interest rates, expected and unexpected inflation, industrial production, and the spread between high- and low-grade bonds are significantly priced and able to explain the variations in the stock market.

As argued, the empirical failure of the CAPM may be also attributed to the static nature of this model and hence its inability to capture time-varying risk premia or correlation structures. There are several models put forth in the literature that use conditioning variables in order to improve the cross-sectional power of asset-pricing models. ${ }^{6}$

Wang (2005) provides an extensive overview of both strains of the literature, including multi-factor models and models with conditioning variables. In his paper, Wang runs a horse race among models composed of various combinations of eight factors and eight conditioning variables proposed in the literature. He finds that conditional CCAPM conditioning on lagged business income growth has the smallest pricing error in all the tests. ${ }^{7}$

As discussed above, the classical CAPM model does not always hold in practice when used to analyze the markets in developed countries. The markets in emerging markets, including the stock markets in the Visegrad countries, are generally smaller and less liquid compared to the developed markets and so it is likely that the CAPM model, especially in its classical formulation, may not be suitable for estimating the cost of capital for these economies. There have been very few studies analyzing these issues in the emerging markets. Harvey (1995) argues that the emerging markets are characterized by low betas and the CAPM model is not able to capture the relationship between the stock returns in these countries and the market portfolio. Based on this finding there are several studies that analyze various factors that influence the stock returns in the emerging markets and propose models suitable for estimating the cost of capital in these markets. Erb, Harvey, and Viskanta (1995, 1996) find that country credit ratings are significantly related to stock returns, and they propose a model based on these indices. Similarly, Harvey (2004) argues that the country risk rating from the International Country Risk Guide affects the ex-

\footnotetext{
${ }^{5}$ Other authors have shown that the HML and SMB factors may be viewed as proxies for various macroeconomic variables. Liew and Vassalou (2000) and Vassalou (2003) argue that these two factors contain news related to future GDP growth. Petkova (2006), on the other hand, shows that Fama-French factors may proxy for more fundamental macroeconomic risks as they are correlated with innovations in the term spread and default spread.

${ }^{6}$ Dividend yields and term spreads have been successfully used in models by Jagannathan and Wang (1996) and Fama and French (1988). Lettau and Ludvigson (2001) argue that using log consumption to aggregate the wealth ratio (cay) as a conditioning variable in both the CAPM and CCAPM models improves their power in explaining the cross section of average stock returns.

${ }^{7}$ Lewellen and Nagel (2006) and Lewellen, Nagel, and Shanken (2006) provide a critique of the standard asset pricing tests of the conditional CAPM. They point to a number of problems with these tests, including relying exclusively on book-to-market and size-sorted portfolios, which are known to have a strong factor structure, ignoring theoretical restrictions in the cross-sectional slopes, and additional sampling issues. They offer a handful of proposals aimed at improving the rigor of these asset-pricing tests and contrast the results obtained with their "modified" tests with the results found in influential papers in this strain of literature. None of the five influential models proposed in the literature, including the Fama-French model, perform well according to a stricter set of empirical tests.
} 
pected returns in emerging markets and so he incorporates these indices into his version of the CAPM model.

The issue of the relative integration of the emerging markets with the global markets and its implications for the stock returns in these markets has been central in the literature. Bekaert and Harvey (1995) argue that the integration of the emerging markets with the global markets has been a dynamic process and therefore also the cost of capital should be allowed to vary over time as the relative measure of integration with global markets changes. In a more recent paper, Bekaert and Harvey (2000) develop a model in which dividend yields are used as a measure of the equity cost of capital. They find that the cost of capital declines as the emerging markets become more integrated with global markets. In one of the few papers that study the markets in Central and Eastern Europe (CEE), Sokalska (2001) finds that stock prices in the Czech Republic, Hungary, and Poland move together. She argues that local macroeconomic fundamentals are of relatively small importance in those markets and that the key factors influencing the movements of stock prices are exogenous. Specifically, she claims that it is the flow of foreign portfolio capital that can be traced to affect the movement of stock prices in those markets. De Jong and de Roon (2001) link the issue of time-varying market integration with expected returns in emerging markets. ${ }^{8}$ They find, in line with the theory, that increasing market integration (or decreasing market segmentation) leads to lower expected returns and hence a lower cost of capital.

There are some important data and methodological issues that need to be addressed in the Visegrad countries. First, the data available is of relatively short time span, which may influence the plausibility of our results. Second, there is a limited number of stocks traded on these stock exchanges, ${ }^{9}$ which makes some of the commonly used portfolio techniques difficult to apply. Taking these considerations into account, we used the Fama MacBeth (1973) (FMB) procedure to estimate our models. This procedure is extensively used by researchers to estimate factor risk premia in the analysis of linear factor models. Shanken (1985) and Shanken (1992) were the first papers to provide a rigorous econometric analysis of the FMB procedure. Jagannathan and Wang (1998) modify the standard FMB estimation to allow for conditional heteroskedasticity of the time-series regression residuals. Skoulakis (2005) demonstrates that the standard FMB method provides reliable $t$-statistics under various scenarios, including small-sample estimates.

The FMB method has several advantages. It gives unbiased estimates even when there is a correlation between observations on different firms in the same year. It also accounts for the variation coming from both time-series and cross-section regressions, which is especially important when there is a limited number of observations, as is the case with the Visegrad countries' data.

In this paper we first estimated the CAPM by the standard FMB procedure to see how this model performs in the stock markets of the Visegrad countries. As

\footnotetext{
${ }^{8}$ They develop a model in which expected returns depend on the degree of market segmentation, measured as the ratio of assets in a given market that cannot be traded by foreign investors. Given that the degree of segmentation changes over time, they allow the expected returns also to vary with time. Using data from 30 emerging markets, including the Visegrad countries, de Jong and de Roon provide evidence that market segmentation has a significant effect on the expected returns.

${ }^{9}$ The variability in the number of stocks traded in the sample is given in Figure 1 and Table 1 .
} 


\section{Figure 1 Average Number of Stocks}

Annual average number of stocks (companies) for each of the Visegrad countries is reported. The sample spans from February 1994 to December 2007. The number of stocks in each month varies from 2 to 74 .

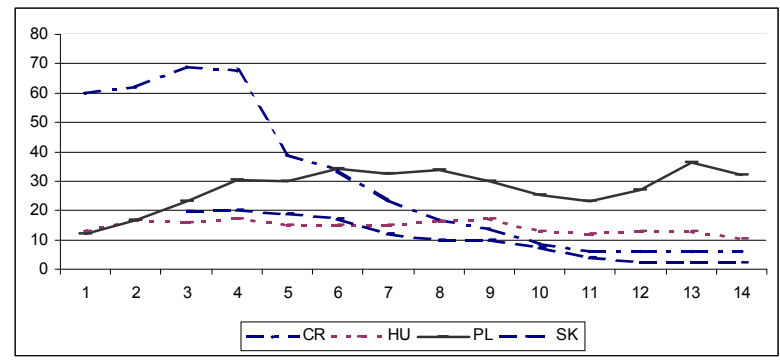

expected, the market factor alone was not able to explain the average stock returns. Given these results we proceeded to the estimation of various macroeconomic factor models. It turned out that different macroeconomic factors are priced in each of the Visegrad countries. Multi-factor models perform much better than the simple CAPM in explaining the average stock returns in these countries. In addition, we employed models with principal components as factors.

This paper is organized as follows. In Section 2 we discuss the CAPM and factor models in greater detail, as well as the testing procedures. In Section 3 we introduce the data and discuss some of its limitations that make the use of some standard techniques impossible. Section 4 contains the empirical results from testing the CAPM and factor models in the Visegrad countries. In Section 5, we briefly summarize the findings of this paper and suggest some directions for further research.

\section{Methodology}

The main objective of this paper is to identify a suitable asset-pricing model that can be used to estimate the cost of equity capital in the Visegrad countries. The first candidate is the Capital Asset Pricing Model (CAPM). According to this classical model specification, the expected return on a security or on a portfolio of securities should be equal to the risk-free rate plus a risk premium, which consists of the portfolio's beta multiplied by the expected excess return of the market portfolio (the return on the market portfolio minus the risk-free rate). Specifically, for the expected return of asset $i, E\left(r_{i t}\right)$, we have:

$$
E\left(r_{i t}\right)-r_{t}^{f}=\beta_{i}\left(E\left(r_{t}^{m}\right)-r_{t}^{f}\right)
$$

where $E\left(r_{i t}\right)$ is the expected return of the $i$-th stock $(i=1 \ldots N), N$ is the number of individual stocks traded in each country, $r_{t}^{f}$ is the risk-free rate, and $E\left(r_{t}^{m}\right)$ is the expected market return. This model can be empirically tested using the following regression equation:

$$
r_{i t}-r_{t}^{f}=\alpha_{i}+\beta_{i}^{m}\left(r_{t}^{m}-r_{t}^{f}\right)+\varepsilon_{i t}
$$

where $r_{i t}-r_{t}^{f}$ is the excess market return on the $i$-th stock, $r_{t}^{m}$ is the market return, $\alpha_{i}$ is the constant term, $\beta_{i}{ }^{m}$ is the coefficient on the excess market return for each of 
the $i$ stocks, and $\varepsilon_{i t}$ is the error term. Individual assets are assumed to be temporally i.i.d., although contemporaneous correlation across assets is allowed $E\left(\varepsilon_{i t} \varepsilon_{j t}\right) \neq 0$. The null hypothesis is that $\alpha_{i}=0$. If this is the case, the pricing errors are zero and the CAPM is said to hold empirically. In addition, the coefficient on the excess market return should be statistically significant, indicating that the model has explanatory power.

In our analysis, we considered an extension of the classical CAPM - a multi-factor model. Suppose there are $k$-factors that are believed to influence the stock returns in a given market. The $k$-factor model can be tested by using the following regression equation:

$$
r_{i t}-r_{t}^{f}=\alpha_{i}+\beta_{i}^{m}\left(r_{t}^{m}-r_{t}^{f}\right)+\sum_{k=2}^{K} \beta_{i}^{k}\left(r_{t}^{k}\right)+\varepsilon_{i t}
$$

where $r_{t}^{m}$ is the local index return, $r_{t}^{k}$ is the $k$-th factor return $(k=2 \ldots K), r_{i t}$ is the return of the $i$-th stock, $r_{t}^{f}$ is the risk-free rate, $\alpha_{i}$ is the constant term, and $\varepsilon_{i t}$ is the error term. Similarly to the CAPM, this multi-factor model predicts that the constant terms, $\alpha_{i}$, should be insignificant $\left(H_{0}: \alpha_{i}=0\right)$. In addition, the coefficients on the excess market return and factor returns should be statistically significant, indicating that the model has explanatory power.

In the literature one can find several ways of testing capital asset pricing models. They can be divided into the following three categories: tests involving time-series regression, tests involving cross-sectional regression, and tests involving a combination of the two. ${ }^{10}$ One of the most widely used methods is the Fama-MacBeth (FMB) procedure, which combines time-series and cross-section regressions. Suppose we have $N$ firms returns for any given month $t, R_{t}$. In the first stage we regress the excess stock return on the excess market return and other $k$-factors in order to obtain the CAPM cross-section betas, $\hat{\beta}_{i}^{m}$ and $\hat{\beta}_{i}{ }^{k}$, where $i$ is the firm subscript $(i=$ $=1 \ldots N), m$ stands for the market return, and $k$ is the factor subscript $(k=2 \ldots K) .{ }^{11}$ In the second stage we run the following cross-sectional Ordinary Least Squares (OLS) regression for any single month $t$ :

$$
R_{i}=\gamma_{0}+\gamma^{m} \hat{\beta}_{i}^{m}+\gamma^{k} \hat{\beta}_{i}^{k}+\eta_{i}
$$

where

$$
\begin{aligned}
& R_{i}=\left(R_{1}, R_{2}, \ldots, R_{N}\right) \text { is an } \mathbf{N} \mathbf{x} \mathbf{1} \text { vector of cross-section excess monthly stock } \\
& \text { returns; } \\
& \hat{\beta}_{i}^{m} \text { and } \hat{\beta}_{i}^{k} \text { are } \mathbf{N} \mathbf{K} \text { matrices of CAPM betas (obtained in the first-stage re- } \\
& \quad \text { gressions); }
\end{aligned}
$$

\footnotetext{
${ }^{10}$ A detailed discussion of these various methods, including the Fama-MacBeth procedure, can be found in Cuthbertson and Nitzsche (2001).

${ }^{11}$ The first-stage regressions are based on 2-year window regressions, assuming that the betas are relatively stable over that time period. Empirical tests developed in the literature often assume this window to be even longer, i.e., 5 years. See Lewellen and Nagel (2005) for a more detailed discussion of high-frequency changes in betas.
} 
$\gamma^{m}$ and $\gamma^{k}$ are vectors of cross-section coefficients for each of the $k$-factors;

$\gamma_{0}$ is a scalar and an estimate of the intercept;

$\eta_{i}$ is an $\boldsymbol{N} \boldsymbol{x} \mathbf{1}$ vector of cross-section error terms.

Then we repeat this regression as in (4) for each month $t=1,2, \ldots T$ and obtain $T$ estimates of $\gamma_{0}, \boldsymbol{\gamma}^{m}$, and $\boldsymbol{\gamma}^{k}$. Finally, we test the following null hypothesis $H_{0}$ : $E\left(\gamma_{0}\right)=0$, i.e., pricing errors are zero, indicating that the model holds empirically. In addition, for the model to have explanatory power, we test whether the market return and other factors are statistically significant. Assuming the returns are i.i.d. and normally distributed the following $t$-statistic is used:

$$
t_{\gamma}=\frac{\overline{\hat{\gamma}}^{k}}{\sigma\left(\hat{\gamma}^{k}\right)}, \quad \text { where } \quad \sigma^{2}\left(\hat{\gamma}^{k}\right)=\frac{1}{T(T-1)} \sum_{t=1}^{T}\left(\hat{\gamma}^{k}-\overline{\hat{\gamma}}^{k}\right)^{2}
$$

Similarly, one can obtain $t$-statistics $t_{\gamma}$ for $\gamma^{m}$ and $\gamma_{0}$ and test all of the CAPM restrictions. $^{12}$

The FMB method has several advantages. It uses all the information available for a given data point, accounting for the variation coming from both sources: time-series and cross-section. Given the relatively short time spans of the data available for the stock markets in the Visegrad countries, it is key to be able to use all the available data points to the maximum. More importantly, this method corrects for cross-sectional correlation in the panel.

There is one important caveat to the FMB approach. Since the estimates of betas, $\widehat{\boldsymbol{\beta}}_{i}{ }^{\boldsymbol{m}}$ and $\widehat{\boldsymbol{\beta}}_{i}{ }^{k}$, obtained in the first-stage regressions may be measured with error, we may encounter the "errors-in-variables" problem in the second-stage regressions. Specifically, if the estimates of $\overline{\boldsymbol{\beta}}_{i}^{m}$ and $\widehat{\boldsymbol{\beta}}_{i}^{k}$ that we use in the second-stage regressions contain measurement error, then the estimates $\gamma^{m}$ and $\gamma^{k}$ will be biased. ${ }^{13} \mathrm{~A}$ traditional approach to minimizing this problem is to group the stocks into portfolios ${ }^{14}$ and estimate the portfolio betas instead of the stock betas in the first-stage regression. Then, in the second stage, the average excess return $\bar{r}_{i}-\bar{r}^{f}$ for each of the stocks is regressed on the appropriate portfolio beta. This approach reduces the measurement error but it does not completely resolve this problem since it still uses beta estimates from the first step in the second-step regressions. Due to the limited number of companies listed on the Visegrad stock exchanges, there are not enough observations at each point of time to form portfolios of individual stocks. As a result, our estimates are based on the individual stock betas (i.e., not the portfolio betas).

${ }^{12} t$-tests of $\gamma^{m}$ and $\gamma_{0}$ will be misspecified when there is cross-sectional dependence in the error terms (when $\left.\operatorname{Cov}\left(\eta_{i}, \eta_{j}\right)=0 ; i \neq j\right)$. Therefore, we calculate and test the time-series averages of $\gamma^{m}$ and $\gamma_{0}$ (simple $t$-tests).

${ }^{13}$ In the least squares regressions, the errors in variables are likely to cause the estimates of the slope coefficients to be biased downward and the estimate of the constant term to be biased upward.

14 The portfolios can be formed based on the size, beta or book-to-market ratio of individual stocks obtained from running the time-series regressions. 
A superior method for dealing with the errors-in-variables problem is the Generalized Method of Moments (GMM), which allows for simultaneous estimation of betas and gammas and therefore avoids the two-stage procedure altogether. Given that our FMB estimates may be biased due to the errors-in-variables problem, we provide GMM estimates to support our results and to highlight the likely impact of the bias. The GMM estimator is defined by minimizing the following criterion function: ${ }^{15}$

$$
\sum_{t} m\left(y_{t}, \theta\right) A\left(y_{t}, \theta\right) m\left(y_{t}, \theta\right)
$$

where $m\left(y_{t}, \theta\right)$ are a set of moment conditions that parameters $\theta$ should satisfy and $A$ is a weighting matrix. ${ }^{16}$ Following Cochrane (2005) we write the moment conditions in the following way:

$$
\left[\begin{array}{c}
E\left(R_{t}^{e}-\alpha-\beta f_{t}\right) \\
E\left[\left(R_{t}^{e}-\alpha-\beta f_{t}\right) f_{t}\right] \\
E\left(R^{e}-\beta \gamma\right)
\end{array}\right]=\left[\begin{array}{l}
0 \\
0 \\
0
\end{array}\right]
$$

These moment conditions are written assuming one asset and one factor but can be easily extended to include $N$ assets and $K$ factors. In such a system there would be $N(1+K+1)$ moment conditions since for each asset $N$ we would have one moment condition for the constant, $K$ moment conditions for the $K$ factors, and one moment condition that allows us to estimate the gammas (the asset-pricing model condition). On the other hand, there would be $N(1+K)+K$ parameters and hence $n-K$ overidentifying restrictions. They can be tested with a chi-square test (the $J$-test for overidentifying restrictions). In this paper we use the GMM estimates to support our results and to underline that our FMB estimates are likely to be biased downward and therefore present a rather conservative estimate of the importance of the various factors. We present alternative results obtained for Poland using one-step GMM estimation, in which the White's optimal weighting matrix is obtained in an iterative process by sequential updating of the coefficients. ${ }^{17}$

To summarize, in this paper we estimate several alternative models, including the classical CAPM, macroeconomic factor models, and the principal factor model, using the Fama-MacBeth procedure with individual stocks (i.e., without sorting the stocks into portfolios). This procedure is, however, prone to the errors-in-variables problem due to its two-stage estimation. In order to support our results, we obtained alternative estimates for Poland using the GMM one-step procedure, which allowed us to assess the potential importance of the errors in variables in our models.

\footnotetext{
${ }^{15}$ See Davidson and MacKinnon (1993) for a more detailed discussion of GMM estimation.

${ }^{16}$ While any symmetric positive definite matrix $\boldsymbol{A}$ will yield a consistent estimate of $\theta$, it is possible to show that in order to obtain an asymptotically efficient estimate of $\theta$ matrix $\boldsymbol{A}$ should be equal to the inverse of the covariance matrix of the sample moments. There are various methods of estimating this covariance matrix, including White's heteroskedasticity-consistent matrix and the heteroskedasticity and autocorrelation (HAC)-consistent matrix.

${ }^{17}$ Unfortunately, we were not able to obtain similar estimates for other Visegrad countries due to the variance-covariance matrices not being positive definite, hence not invertible.
} 


\section{Data}

Data on individual stocks as well as local market indices needed in order to test the validity of the classical CAPM in Visegrad countries were obtained from Wharton Research Data Services. Other data were obtained from the IMF's International Financial Statistics Database and from national bank and ministry of finance websites. A summary of these variables is presented in Table 1 (the first three variables in each country).

As argued, the classical, one-factor CAPM does not always hold empirically and therefore various multi-factor models have been proposed in the literature. Fama-French factors are the most commonly used in the literature as they turn out to be the most successful empirically. In order to obtain these factors the stocks need to be grouped into portfolios on the basis of the firm's size and book-to-market value. Due to the limited number of stocks traded in the stock markets of the Visegrad countries, the portfolio grouping may not be optimal.

Therefore, in this paper a second-best approach is used, namely, the macroeconomic factor model. It has been noted that observable economic time series such as inflation and interest rates can be used as measures of pervasive and common factors in stock returns. Chen, Roll, and Ross (1986) argue that stock prices can be expressed as expected discounted dividends:

$$
p=\frac{E(c)}{k}
$$

where $c$ is the dividend stream and $k$ is the discount factor. From this it can be deduced that the economic variables that influence the discount factors as well as the expected cash flows will also influence the expected returns. Chen, Roll, and Ross (CRR) use the following factors: industrial production growth, a measure of unexpected inflation, changes in expected inflation, the difference in returns on low-grade corporate bonds and long-term government bonds (risk premia), the difference in returns on long-term government bonds and short-term Treasury bills (term structure), changes in real consumption, and oil prices. In our factor model, similarly to CRR, we included monthly industrial growth and the term structure. In contrast to CRR, we did not include two inflation variables in order to avoid likely correlations between them. Instead, we used only monthly inflation. Since there is no time-series data on corporate bond grading in the Visegrad countries, we did not incorporate any measure of risk premia into our model. ${ }^{18}$ To summarize, in our baseline factor model we used the following four factors: the market return, the monthly growth rate of industrial production, inflation, and the term structure. Changes in the level of industrial production affect the real value of cash flows. In addition, a direct link between returns and production is specified in the business cycle models. Inflation influences the nominal value of cash flows as well as the nominal interest rate. Finally, the discount rate is affected by changes in the term structure spreads between different

${ }^{18}$ Omitting risk premia in the model specification is likely to result in omitted variable bias in the coefficient on the term structure (being the variable most highly correlated with the risk premia according to CRR). This bias is likely to be negative as, according to CRR, the correlation between these two variables is negative and the likely sign of the coefficient on the risk premia is positive. All the other variables (the excess market return, inflation, and industrial production) are positively correlated with risk premia and therefore omitting risk premia is likely to create upward bias in the coefficients on these variables. 


\section{Table 1 Summary Statistics: CAPM and Factor Models}

Sample mean, standard deviation, and maximum and minimum values are reported for the variables used in the CAPM and multi-factor model regression. These statistics are reported for the cross-sectional distribution, where the number of firms varies from 2 to 74 depending on the country. All the variables are monthly returns or growth rates in local currency. All the series were tested for the presence of unit roots by the Augmented Dickey-Fuller test for trend stationarity. Stock_rt stands for stock return, market_rt is the local market return, and $t$-bill is the monthly return on short-term government securities. The time series for the term structure was obtained by subtracting the monthly return on Treasury bills from the monthly return on long-term government bonds. In the subsequent statistical analysis CPI inflation and the term structure were used in first differences since their original time series contain unit roots. Indprod stands for the monthly industrial production growth rate, infl represents monthly growth in inflation, ts is the term structure, exrate is the monthly appreciation/depreciation of the national currency against the euro, ger_indprod stands for monthly industrial production growth in Germany, money represents monthly growth in $\mathrm{M} 1$, commod stands for monthly growth in the all primary commodities index, and exports is the monthly growth in exports.

\begin{tabular}{|c|c|c|c|c|c|}
\hline Variable & Obs. & Mean & Std. Dev. & Min. & Max. \\
\hline \multicolumn{6}{|c|}{ Czech Republic; Feb 1994-Dec 2007; No of Companies: 6-74 } \\
\hline stock_rt & 4942 & -0.0060 & 0.1649 & -0.9250 & 10.5352 \\
\hline markèt_rt & 4942 & -0.0052 & 0.0732 & -0.2318 & 0.2275 \\
\hline local t-bill & 4942 & 0.0070 & 0.0028 & 0.0014 & 0.0129 \\
\hline indprod & 4936 & 0.0088 & 0.0935 & -0.2390 & 0.2141 \\
\hline infl & 4942 & 0.0056 & 0.0068 & -0.0078 & 0.0402 \\
\hline ts & 4942 & 0.0005 & 0.0011 & -0.0032 & 0.0036 \\
\hline exrate & 4942 & 0.0008 & 0.0181 & -0.0536 & 0.0677 \\
\hline ger_indprod & 4936 & 0.0061 & 0.0747 & -0.1130 & 0.1914 \\
\hline money & 4936 & 0.0068 & 0.0329 & -0.1049 & 0.2437 \\
\hline exports & 4942 & 0.0217 & 0.1137 & -0.3016 & 0.2922 \\
\hline commod & 4955 & 0.0035 & 0.0299 & -0.0990 & 0.0907 \\
\hline \multicolumn{6}{|c|}{ Hungary; Feb 1993-Dec 2007; No of Companies: 9-18 } \\
\hline stock_rt & 2409 & 0.0173 & 0.1619 & -0.9000 & 2.2605 \\
\hline market rt & 2409 & 0.0250 & 0.0969 & -0.3606 & 0.5809 \\
\hline local t-bill & 2409 & 0.0128 & 0.0066 & 0.0045 & 0.0283 \\
\hline indprod & 2548 & 0.0117 & 0.0915 & -0.1952 & 0.2619 \\
\hline infl & 2558 & 0.0093 & 0.0089 & -0.0039 & 0.0439 \\
\hline ts & 1857 & -0.0014 & 0.0012 & -0.0042 & 0.0009 \\
\hline exrate & 2558 & 0.0056 & 0.0201 & -0.0508 & 0.1220 \\
\hline ger_indprod & 2548 & 0.0050 & 0.0718 & -0.1130 & 0.1914 \\
\hline money & 2548 & 0.0122 & 0.0294 & -0.1013 & 0.0938 \\
\hline exports & 2538 & 0.0284 & 0.1287 & -0.2921 & 0.4532 \\
\hline commod & 2559 & 0.0059 & 0.0351 & -0.0990 & 0.0907 \\
\hline \multicolumn{6}{|c|}{ Poland; Feb 1993-Dec 2007; No of Companies: 9-37 } \\
\hline stock_rt & 4624 & 0.0158 & 0.1621 & -0.9280 & 1.8950 \\
\hline market_rt & 4624 & 0.0204 & 0.1064 & -0.3526 & 1.0593 \\
\hline local t-bill & 4624 & 0.0110 & 0.0066 & 0.0032 & 0.0278 \\
\hline indprod & 4751 & 0.0082 & 0.0661 & -0.1989 & 0.2091 \\
\hline infl & 4751 & 0.0064 & 0.0085 & -0.0090 & 0.0560 \\
\hline ts & 4624 & -0.0010 & 0.0016 & -0.0055 & 0.0016 \\
\hline exrate & 4751 & 0.0022 & 0.0259 & -0.0426 & 0.1192 \\
\hline ger_indprod & 4719 & 0.0052 & 0.0706 & -0.1130 & 0.1914 \\
\hline money & 4719 & 0.0167 & 0.0345 & -0.1086 & 0.1554 \\
\hline exports & 4719 & 0.0201 & 0.0907 & -0.1692 & 0.2913 \\
\hline commod & 4752 & 0.0068 & 0.0375 & -0.0990 & 0.0907 \\
\hline
\end{tabular}




\begin{tabular}{|c|c|c|c|c|c|}
\hline Variable & Obs. & Mean & Std. Dev. & Min. & Max. \\
\hline \multicolumn{6}{|c|}{ Slovak Republic; Feb 1996-Dec 2007; No of Companies: 2-20 } \\
\hline stock_rt & 1476 & 0.0020 & 0.1912 & -0.9811 & 2.1395 \\
\hline market_rt & 1476 & -0.0001 & 0.0610 & -0.1708 & 0.3582 \\
\hline local t-bill & 1476 & 0.0104 & 0.0053 & 0.0022 & 0.0217 \\
\hline indprod & 1476 & 0.0057 & 0.0621 & -0.1441 & 0.1621 \\
\hline infl & 1476 & 0.0060 & 0.0093 & -0.0037 & 0.0569 \\
\hline ts & 1358 & 0.0003 & 0.0019 & -0.0041 & 0.0079 \\
\hline exrate & 1358 & 0.0010 & 0.0135 & -0.0370 & 0.0358 \\
\hline ger_indprod & 1474 & 0.0057 & 0.0715 & -0.1130 & 0.1650 \\
\hline money & 1474 & 0.0076 & 0.0460 & -0.1158 & 0.3779 \\
\hline exports & 1476 & 0.0187 & 0.1004 & -0.2309 & 0.2492 \\
\hline commod & 1513 & 0.0028 & 0.0352 & -0.0990 & 0.0907 \\
\hline
\end{tabular}

maturities. In addition, we estimated alternative factor models, which included variables that we believe may be important in Visegrad countries. The additional variables included: the exchange rate, the all primary commodities index, ${ }^{19}$ German industrial production, money, and exports. Given that all these countries are relatively small, open economies, fluctuations in the exchange rate, commodity prices, exports, and the money base are likely to have a strong impact on other macroeconomic variables. The economic situation in Germany (proxied by its industrial production), one of the most important trading partners for the Visegrad countries, may have a significant impact on the economies of these countries and therefore may also influence their stock markets. The time series of all these additional variables were obtained from the IMF International Financial Statistics Database. A summary of these variables is presented in Table 1.

In order to overcome the limitations of factor models with respect to the small number of variables that can be used in the estimation, we employed principal component analysis to extract the main factors driving the economies of the Visegrad countries. This method is mainly used for forecasting purposes. It is based on the principle that there are a few forces driving the dynamics of all macroeconomic series. Since these forces are unobservable they need to be estimated from a large number of economic time series. Given that the Visegrad markets are transition economies and there is a limited span of data available, principal component analysis may be very useful for explaining the stock returns in these countries. The first three principal factors, which explained most of the variance of the average stock returns, were used as the factors in the alternative multi-factor model (principal factor model). In addition, the same number of factors as the baseline multi-factor model allowed a direct comparison of the performance of these two models. ${ }^{20}$

\footnotetext{
${ }^{19} \mathrm{CRR}$ also consider changes in consumption and oil prices in their model but find that these variables are not significantly related to the stock returns. Due to a lack of available data on consumption we did not include it in the analysis. For oil prices we decided to use the following proxy: the All Primary Commodities Index from the IMF.

${ }^{20}$ The list of variables used to obtain the principal factors as well as a short description of the methodology is included in the Appendix available at the website of this journal: http://journal.fsv.cuni.cz/. In addition, the summary statistics of the first three principal factors used in the principal factor model are available upon request.
} 


\section{Table 2 Results: CAPM}

We estimated the CAPM by the FMB procedure using the following regression equation: $r_{i t}-r_{t}^{f}=\alpha_{i}+\beta_{i}^{m}\left(r_{t}^{m}-r_{t}^{f}\right)+\varepsilon_{i t}$, where $r_{i t}$ is the $i$-th stock return $(i=1 \ldots . N), r_{t}^{f}$ is the risk-free rate, $r_{t}^{m}$ is the market return $\alpha_{i}$ is the constant term and $\varepsilon_{i t}$ is the error term. In the first stage, we regressed the excess stock return $r_{i t}-r_{t}^{f}$ on the excess market return $r_{t}^{m}-r_{t}^{f}$ in order to obtain the CAPM betas, $\hat{\beta}_{i}$, where $i$ is the firm's subscript. These beta estimates were then used in the second stage as the independent variables in the following regression equation: $r_{i}-r^{f}=\gamma_{0}+\gamma^{m} \hat{\beta}_{i}^{m}+\eta_{i}$. This regression was repeated for each month and we obtained $T$ estimates of $\gamma_{0}$ and $\gamma^{m}$. Specifically, first beta estimates were obtained for the first 24 months of data and then used to calculate the gammas ( $\gamma_{0}$ and $\gamma^{m}$ ) for the twenty-fourth month. Then, the betas were obtained for the period from the second to the twenty-fifth month and used in the second stage to estimate obtain the gammas for the twenty-fifth month. This procedure of rolling regressions with a fixed window of twenty-four months was used to cover the whole data sample. Finally, we tested the averages of these $T$ estimates to see if: $E\left(\gamma_{0}\right)=0$ (i.e. pricing errors are zero) and $E\left(\gamma^{m}\right)>0$ (i.e. a positive risk premium on the excess market return). The monthly return on the local index was used as a proxy for the market portfolio return and the monthly return on the local $T$-bill was used as the risk-free rate. In Table 2 we report the average slopes and $t$-statistics (in parenthesis) from the month-by-month regressions of the excess stock returns on the betas of the excess market returns. ${ }^{*},{ }^{* *}$, and ${ }^{* * *}$ indicate a significant difference at the 10,5 , and 1 percent levels, respectively.

\begin{tabular}{|c|c|c|c|c|}
\hline Country & Sample & $\begin{array}{l}\text { Local index } \\
\left(\gamma^{m}\right)\end{array}$ & $\begin{array}{c}\text { Constant } \\
\left(\gamma_{0}\right)\end{array}$ & Adjusted $R^{2}$ \\
\hline $\begin{array}{l}\text { Czech Republic } \\
\text { (4942 obs.) }\end{array}$ & Feb 1994-Dec 2007 & $\begin{array}{c}0.0000 \\
(0.6305)\end{array}$ & $\begin{array}{l}0.0063 \\
\left(1.7814^{\star \star}\right)\end{array}$ & 0.1167 \\
\hline $\begin{array}{l}\text { Hungary } \\
\text { ( } 2409 \text { obs.) }\end{array}$ & Feb 1993-Dec 2007 & $\begin{array}{c}0.0140 \\
\left(1.5430^{\star}\right)\end{array}$ & $\begin{array}{c}-0.0099 \\
\left(-1.3281^{*}\right)\end{array}$ & 0.1090 \\
\hline $\begin{array}{l}\text { Poland } \\
\text { (4624 obs.) }\end{array}$ & Feb 1993-Dec 2007 & $\begin{array}{l}0.0034 \\
(0.4008)\end{array}$ & $\begin{array}{c}-0.0034 \\
(-0.5485)\end{array}$ & 0.0954 \\
\hline $\begin{array}{l}\text { Slovak Republic } \\
\text { (1476 obs.) }\end{array}$ & Feb 1996-Dec 2007 & $\begin{array}{l}-0.0822 \\
\left(-2.2423^{* \star}\right)\end{array}$ & $\begin{array}{l}0.0696 \\
\left(2.7071^{* \star *}\right)\end{array}$ & 0.0046 \\
\hline
\end{tabular}

\section{Estimation}

The CAPM (single-factor model) was estimated using the regression equation (2) by the FMB procedure, where local market indices (obtained from Wharton Research Data Services) were used as proxies for the market portfolio ${ }^{21}$ and monthly returns on local T-bills represented the risk-free rate. The results obtained for the four Visegrad markets are presented in Table 2.

These results indicate that the CAPM holds $\left(H_{0}: E\left(\gamma_{0}\right)=0\right.$ should not be rejected) in Poland. However, the coefficient on the excess market return is insignificant, indicating a lack of explanatory power. The CAPM should be rejected for the other Visegrad countries, as the constant terms were statistically different from

${ }^{21}$ Initially we considered using the following three alternative variables as a proxy for the market portfolio: the local market index, the S\&P 500 index, and the MSCI world index. We tested these various specifications for the Visegrad markets and found that the choice of market proxy did not influence the validity of the CAPM. Our findings are consistent with Low and Nayak (2005), who show that the choice of market portfolio is irrelevant for the validity of the CAPM. Therefore, we proceeded with the local market index as a proxy for the market portfolio. 


\section{Table 3 Results: Baseline Multi-Factor Models}

We estimated the four-factor model by the FMB procedure using the following regression equation: $r_{i t}-r_{t}^{f}=\alpha_{i}+\beta_{i}^{m}\left(r_{t}^{m}-r_{t}^{f}\right)+\beta_{i}{ }^{2}\left(r_{t}^{2}\right)+\ldots . .+\beta_{i}^{4}\left(r_{t}^{4}\right)+\varepsilon_{i t}$, where $r_{t}^{m}$ is the local index return, $r_{t}^{k}$ is the $k$-th factor return $(k=2 \ldots 4), r_{i t}$ is the $i$-th stock return, $r_{t}^{f}$ is the risk-free rate, $\alpha_{i}$ is the constant term, and $\varepsilon_{i t}$ is the error term. The monthly return on the local index was used as a proxy for the market portfolio return and the monthly return on the local $T$-bill was used as the risk-free rate. We considered the following four factors: excess market return, inflation, industrial production, and term structure. All the series are monthly growth rates or monthly returns. Inflation and term the structure are used in first differences since the unit root tests detected nonstationarity in these series. Similarly to the CAPM, this multi-factor model predicts that the constant terms, should be insignificant and the slope coefficients should be significantly different from zero. In the first stage, we regressed the excess stock return $r_{i t}-r_{t}^{f}$ on the four factors in order to obtain the betas, $\hat{\beta}_{i}^{m}$ and $\hat{\beta}_{i}^{f}$, where $i$ is the firm's subscript, $m$ indicates the excess market return, and $f$ is the factor subscript $(f=2 \ldots 4)$. These beta estimates were then used in the second stage as the independent variables in the following regression equation: $r_{i}-r^{f}=\gamma_{0}+\gamma^{m} \hat{\beta}_{i}^{m}+\gamma^{f} \hat{\beta}_{i}^{f}+\eta_{i}$. This regression was repeated for each month and we obtained $T$ estimates of $\gamma_{0}, \gamma^{m}$ and $\gamma^{f}$ (for each of the factors $f$ ). Specifically, the first beta estimates were obtained for the first 24 months of data and then used to calculate the gammas $\left(\gamma_{0}, \gamma^{m}\right.$ and $\left.\gamma^{f}\right)$ for the twenty-fourth month. Then, the betas were obtained for the period from the second to the twenty-fifth month and used in the second stage to estimate the gammas for the twenty-fifth month. This procedure of rolling regressions with a fixed window of twenty-four months was used to cover the whole data sample. Finally, we tested the averages of these $T$ estimates to see if: $E\left(\gamma_{0}\right)=0$ (i.e. pricing errors are zero), $E\left(\gamma^{m}\right)>0$ and $E\left(\gamma^{f}\right)>0$ (i.e. a positive risk premium on the excess market return and other factors $f$ ). In Table 3 we report the average slopes and $t$-statistics (in parenthesis) from the month-by-month regressions of the excess stock returns on the betas of the excess market returns, inflation, industrial production, and the term structure. ${ }^{*},{ }^{* *}$, and ${ }^{* * *}$ indicate a significant difference at the 10,5 , and 1 percent levels, respectively.

\begin{tabular}{lcccccc}
\hline $\begin{array}{l}\text { Countryl } \\
\text { Adj. } \mathbf{R}^{\mathbf{2}}\end{array}$ & Sample & $\begin{array}{c}\text { Excess Market } \\
\text { Return } \\
\left(\gamma^{m}\right)\end{array}$ & $\begin{array}{c}\text { Inflation } \\
\left(\gamma^{2}\right)\end{array}$ & $\begin{array}{c}\text { Ind. Prod. } \\
\left(\gamma^{3}\right)\end{array}$ & $\begin{array}{c}\text { Term } \\
\text { Structure } \\
\left(\gamma^{4}\right)\end{array}$ & $\begin{array}{c}\text { Constant } \\
\left(\gamma_{0}\right)\end{array}$ \\
\hline Czech & Feb 94-Dec 07 & 0.0016 & -0.0010 & -0.0115 & -0.0001 & 0.0002 \\
Republic & $(4936$ obs. $)$ & $(0.2035)$ & $(-0.6687)$ & $(-0.4836)$ & $(-1.0935)$ & $(0.0301)$ \\
$(0.1203)$ & Feb 93-Dec 07 & 0.0111 & -0.0018 & -0.0071 & 0.0001 & -0.0081 \\
Hungary & $(1829$ obs. $)$ & $(1.0264)$ & $(-1.0926)$ & $(-0.3117)$ & $(1.1913)$ & $(-0.9357)$ \\
$(0.1387)$ & Feb 93-Dec 07 & 0.0089 & 0.0017 & -0.0065 & 0.0000 & -0.0054 \\
Poland & $(4612$ obs. $)$ & $(1.1506)$ & $\left(2.0011^{* *}\right)$ & $(-0.9165)$ & $(-1.0032)$ & $(-0.9771)$ \\
$(0.1001)$ & Feb 96-Dec 07 & -0.0168 & -0.0072 & 0.0279 & -0.0006 & 0.0196 \\
Slovak & $(1338$ obs.) & $(-1.1553)$ & $\left(-1.5274^{*}\right)$ & $\left(1.3154^{*}\right)$ & $(-1.2609)$ & $(1.2624)$ \\
$\begin{array}{l}\text { Republic } \\
(0.0058)\end{array}$ & & & & & & \\
\hline
\end{tabular}

zero $\left(E\left(\gamma_{0}\right) \neq 0\right)$. The poor performance of the CAPM model is not surprising and is in line with the literature covering the behavior of stock exchanges in the second half of the twentieth century. Therefore, we extended the single-factor model by adding additional macroeconomic factors. In the baseline factor model, we added the following three variables: industrial production, inflation, and the term structure. This extended four-factor model was also tested by following the FMB procedure. The results from these regressions are presented in Table 3.

The baseline four-factor model holds for all the Visegrad countries, as the null hypothesis $\left(H_{0}: E\left(\gamma_{0}\right)=0\right)$ could not be rejected. In addition, some of the factors 
turned out to be statistically significant in Poland and in Slovakia. In Poland, inflation was able to explain part of the variation in the average stock returns. In Slovakia, two factors - inflation and industrial production - seemed to have some explanatory power. While none of the factors turned out to be significant in the Czech Republic and Hungary, some of the $t$-statistics were quite high, bordering on significance at the 10 percent level (for the term structure in the Czech Republic and for the term structure and inflation in Hungary). These lower values may be due to downward bias caused by the presence of errors in variables resulting from the two-step estimation in the FMB procedure.

Given that few factors turned out to be statistically significant, we proceeded with alternative multi-factor models, in which we included additional variables to the excess market return, including the exchange rate, German industrial production, money, the commodity index, and exports. The results of these alternative estimations are presented in Table 4. As with the baseline four-factor model, these alternative factor models hold for all the Visegrad countries, as the null hypothesis $\left(H_{0}: E\left(\gamma_{0}\right)=0\right)$ could not be rejected. For the Czech Republic, a model including money, industrial production, and exports was the most promising, given that all three macroeconomic factors were statistically significant. For the other countries, there are two alternative models that appear equally plausible. For Hungary, the first model includes inflation and the exchange rate, with the latter factor being statistically significant. The other one includes the exchange rate, money, and the commodity index and all these factors turned out significant. In the case of Poland, the first alternative factor model includes inflation and money, in which all these factors are statistically significant, and the second one is expanded by the inclusion of the commodity index as an additional factor (albeit not significant). In the Slovak market, the first model includes industrial production, the term structure, and money, in which the market factor, the term structure, and money were all statistically significant. In addition, a model with inflation, industrial production, the term structure, money, and the commodity index was also plausible, with both inflation and the term structure being statistically significant.

We performed a series of tests of the added explanatory power of the macroeconomic factor models and the CAPM. ${ }^{22}$ For Hungary, Poland, and Slovakia the correct factor model appears to be the baseline four-factor model, which is superior to both the CAPM and the alternative factor models. In the Czech Republic, on the other hand, the baseline four-factor model is strongly rejected in favor of the alternative model with the market factor, industrial production, exports, and money.

In the next stage, we employed principal component analysis to obtain the key factors, ${ }^{23}$ which we then incorporated into a factor model together with the excess market return. This four-factor model (including three principal factors/components and the excess market return) was estimated using the FMB technique. The results of this estimation are presented in Table 5.

According to the results presented in Table 5, Poland was the only country for which the principal factor model had to be rejected, as the constant term was statistically significant $\left(E\left(\gamma_{0}\right) \neq 0\right)$. In spite of the rejection of the model, all factors as

${ }^{22}$ These results are available upon request. 
well as the excess market return were statistically significant. In Czech Republic, the second factor was statistically significant and was driven mainly by developments in imports and exports. In Hungary, the excess market return was significant, as were the second and third factors, which included primarily information on exchange rates, consumer prices, and prices of primary commodities. Finally, in Slovakia, none of the factors turned out to be statistically significant.

As argued, the results obtained by using the FMB procedure are likely to be biased due to the errors-in-variables problem. In order to verify this hypothesis and to support our results we proceeded with an alternative GMM estimation in which all the slope coefficients (betas and gammas) are estimated simultaneously. We obtained satisfactory confirmation of this hypothesis for Poland. For the other countries, however, we were not able to obtain GMM estimates due to data issues. Specifically, it was not possible to obtain the inverses of the variance-covariance matrices of residuals defined in (7) in these systems (these matrices were not positive definite). The estimates obtained for the four-factor model for Poland from the one-step GMM estimation are presented in Table 6.

The results presented in Table 6 support the hypothesis that the FMB estimates of the slope coefficients are likely to be biased downward. The estimates obtained by the one-step GMM for the four factors are in all cases greater than the FMB estimates. More importantly, they all turned out to be statistically significant, as compared with only two factors - inflation and the term structure - being significant in the FMB case. ${ }^{24}$

\footnotetext{
${ }^{23}$ Given the relatively small samples and short time series it is difficult to argue with certainty that these unobservable factors are different across the Visegrad countries. Therefore, the following results should be viewed with caution. In the Czech Republic these three principal components accounted for 56 percent of the variance of the data used for the principal component analysis. The first factor was driven mainly by interest rates, the second by imports and exports, and the third by prices of primary commodities. In Hungary, the three principal factors captured 82 percent of the variance. The first and third factors had similar composition to those for the Czech Republic, while the second factor was driven mainly by exchange rates (forint against USD and EUR) and consumer prices. In Poland, the three factors amounted to 49 percent of the variance. The first one primarily summarized developments in exchange rates (zloty against USD and EUR) and in producer prices. The second factor captured again developments in exchange rates as well as in prices of primary commodities. In Slovakia, the three principal factors captured 72 percent of the overall variance in the data. The first factor summarized movements in prices of primary commodities and the second movements in both consumer and producer prices, while the third contained information mainly on changes in industrial production.

${ }^{24}$ These results are presented for a shorter sample and are meant to serve only for illustrative purposes. Due to the model being weakly identified, we were not able to replicate these results for all the Visegrad countries.
} 


\section{Table 4 Results: Additional Multi-Factor Models}

We estimated the multi-factor model by the FMB procedure using the following regression equation: $r_{i t}-r_{t}^{f}=\alpha_{i}+\beta_{i}^{m}\left(r_{t}^{m}-r_{t}^{f}\right)+\beta_{i}^{2}\left(r_{t}^{2}\right)+\ldots . .+\beta_{i}^{8}\left(r_{t}^{8}\right)+\varepsilon_{i t}$, where $r_{t}^{m}$ is the local index return, $r_{t}^{k}$ is the $k$-th factor return $(k=2 \ldots 8), r_{i t}$ is the $i$-th stock return, $r_{t}^{f}$ is the risk-free rate, $\alpha_{i}$ is the constant term, and $\varepsilon_{i t}$ is the error term. The monthly return on the local index was used as a proxy for the market portfolio return and the monthly return on the local $T$-bill was used as the risk-free rate. Compared to the baseline four-factor model (results in Table 3), we added up to five additional variables: exchange rate, German industrial production, money, the commodity index, and exports. All series represent monthly growth rates or monthly returns. Inflation and the term structure are used in first differences (unless otherwise indicated) since the unit root tests detected nonstationarity in these series. Similarly to the CAPM, this multi-factor model predicts that the constant terms, should be insignificant and the slope coefficients should be significantly different from zero. In the first stage, we regressed the excess stock return $r_{i t}-r_{t}^{f}$ on the four factors in order to obtain the betas, $\hat{\beta}_{i}^{m}$ and $\hat{\beta}_{i}^{f}$, where $i$ is the firm subscript, $m$ indicates the excess market return, and $f$ is the factor subscript $(f=2 \ldots 8)$. These beta estimates were then used in the second stage as the independent variables in the following regression equation: $r_{i}-r^{f}=\gamma_{0}+\gamma^{m} \hat{\beta}_{i}^{m}+\gamma^{f} \hat{\beta}_{i}^{f}+\eta_{i}$. This regression was repeated for each month and we obtained $T$ estimates of the gammas $\left(\gamma_{0}, \gamma^{m}\right.$ and $\left.\gamma^{f}\right)$ for each of the factors $f$. Specifically, the first beta estimates were obtained for the first 24 months of data and then used to calculate the gammas for the twenty-fourth month. Then, the betas were obtained for the period from the second to the twenty-fifth month and used in the second stage to estimate the gammas for the twenty-fifth month. This procedure of rolling regressions with a fixed window of twenty-four months was used to cover the whole data sample. Finally, we tested the averages of these $T$ estimates to see if: $E\left(\gamma_{0}\right)=0$ (i.e. pricing errors are zero), $E\left(\gamma^{m}\right)>0$ and $E\left(\gamma^{f}\right)>0$ (i.e. a positive risk premium on the excess market return and other factors $f$ ). In Table 4 we report the average slopes and $t$-statistics (in parenthesis) from the month-by-month regressions of the excess stock returns on the betas of the excess market returns, inflation, industrial production, the term structure, and the exchange rate, German industrial production, money and exports. ${ }^{*},{ }^{* *}$, and ${ }^{* * *}$ indicate a significant difference at the 10,5 , and 1 percent levels, respectively.

\begin{tabular}{|c|c|c|c|c|c|c|c|c|c|}
\hline $\begin{array}{l}\text { Excess } \\
\text { market } \\
\text { return }\end{array}$ & $\begin{array}{c}\text { Infla- } \\
\text { tion }\end{array}$ & $\begin{array}{l}\text { Ind. } \\
\text { Prod. }\end{array}$ & $\begin{array}{c}\text { Term } \\
\text { Structure }\end{array}$ & $\begin{array}{c}\text { Ex- } \\
\text { change } \\
\text { rate }\end{array}$ & $\begin{array}{c}\text { German } \\
\text { Ind. } \\
\text { Prod. }\end{array}$ & Money & Exports & $\begin{array}{c}\text { Com- } \\
\text { modity } \\
\text { Index }\end{array}$ & $\begin{array}{l}\text { Con- } \\
\text { stant }\end{array}$ \\
\hline
\end{tabular}

Czech Republic; 4936 obs.; Adj. $R^{2}=0.1250$

Term structure, inflation and money in first differences

\begin{tabular}{ccccc}
\hline 0.0044 & -0.0511 & -0.0215 & -0.0412 & -0.0034 \\
$(0.4786)$ & $\left(-2.0116^{\star *}\right)$ & $\left(-2.5540^{\star \star \star}\right)$ & $\left(-1.3224^{\star}\right)$ & $(-0.3803)$ \\
\hline
\end{tabular}

Hungary; 2409 obs. and 2399 obs.; Adj. $R^{2}=0.1124$ and $R^{2}=0.1100$

Term structure, inflation and money in first differences

\begin{tabular}{ccccc}
\hline 0.0055 & 0.0000 & -0.0073 & & 0.0003 \\
$(0.5885)$ & $(-0.0192)$ & $\left(-1.9198^{\star \star}\right)$ & & $(0.0345)$ \\
0.0137 & -0.0061 & -0.0153 & 0.0133 & -0.0075 \\
$(1.2578)$ & & $\left(-1.6248^{*}\right)$ & $\left(-1.3693^{\star}\right)$ & $\left(2.0324^{\star *}\right)(-1.0332)$ \\
\hline
\end{tabular}

Poland; 4592 obs.; Adj. $R^{2}=0.0954$ and $R^{2}=0.0958$

Term structure and inflation in first differences

\begin{tabular}{ccccc}
\hline 0.0075 & 0.0018 & -0.0046 & -0.0020 \\
$(0.9788)$ & $\left(2.4678^{\star \star *}\right)$ & $\left(-1.3227^{\star}\right)$ & $(-0.3682)$ \\
0.0087 & 0.0011 & -0.0062 & 0.0030 & -0.0056 \\
$(0.9623)$ & $\left(1.4898^{\star}\right)$ & $\left(-1.6624^{\star \star}\right)$ & $(0.8225)$ & $(-0.9906)$ \\
\hline
\end{tabular}




\begin{tabular}{|c|c|c|c|c|c|}
\hline \multicolumn{6}{|c|}{$\begin{array}{l}\text { Slovakia; } 1336 \text { obs.; } A d j . R^{2}=0.0047 \text { and } R^{2}=0.0057 \\
\text { Term structure, inflation, money, and exchange rate in first differences }\end{array}$} \\
\hline $0.0032 \quad-0.0122$ & 0.0372 & -0.0011 & 0.0319 & -0.0163 & -0.0122 \\
\hline$(0.2086)\left(-1.8047^{\star \star}\right)$ & $(1.2154)$ & $\left(-2.2190^{\star \star}\right)$ & $(1.2187)$ & $(-0.9600)$ & $(-1.0330)$ \\
\hline-0.0256 & 0.0149 & -0.0012 & 0.0389 & & 0.0192 \\
\hline$\left(-1.7500^{\star \star}\right)$ & $(0.7169)$ & $\left(-2.392^{\star \star *}\right)$ & $\left(1.4128^{*}\right)$ & & (1.2408) \\
\hline
\end{tabular}

\section{Table 5 Results: Principal Factor Models}

We estimated the principal model by the FMB procedure using the following regression equation: $r_{i t}-r_{t}^{f}=\alpha_{i}+\beta_{i}^{m}\left(r_{t}^{m}-r_{t}^{f}\right)+\beta_{i}^{2}\left(r_{t}^{2}\right)+\ldots . .+\beta_{i}^{4}\left(r_{t}^{4}\right)+\varepsilon_{i t}$, where $r_{t}^{m}$ is the local index return, $r_{t}^{k}$ is the $k$-th principal factor return $(k=2 \ldots 4), r_{i t}$ is the $i$-th stock return, $r_{t}^{f}$ is the risk-free rate, $\alpha_{i}$ is the constant term, and $\varepsilon_{i t}$ is the error term. The monthly return on the local index was used as a proxy for the market portfolio return and the monthly return on the local $T$-bill was used as the risk-free rate. We obtained principal factors using the principal component analysis. Then, we used the first three as the principal factors in the asset-pricing model. Similarly to the CAPM, this multi-factor model predicts that the constant terms, should be insignificant and the slope coefficients should be significantly different from zero. In the first stage, we regressed the excess stock return $r_{i t}-r_{t}^{f}$ on the excess market return and on the three first principal factors in order to obtain the betas $\left(\hat{\beta}_{i}^{m}\right.$ and $\left.\hat{\beta}_{i}^{f}\right)$, where $i$ is the firm subscript, $m$ indicates the excess market return, and $f$ is the principal factor subscript $(f=2 \ldots 4)$. These beta estimates were then used in the second stage as the independent variables in the following regression equation: $r_{i}-r^{f}=\gamma_{0}+\gamma^{m} \hat{\beta}_{i}^{m}+\gamma^{f} \hat{\beta}_{i}^{f}+\eta_{i}$. This regression was repeated for each month and we obtained $T$ estimates of $\gamma_{0}, \gamma^{m}$ and $\gamma^{f}$ (for each of the factors $f$ ). Specifically, the first beta estimates were obtained for the first 24 months of data and then used to calculate the gammas $\left(\gamma_{0}\right.$, $\gamma^{m}$ and $\gamma^{f}$ ) for the twenty-fourth month. Then, the betas were obtained for the period from the second to the twenty-fifth month and used in the second stage to estimate the gammas for the twenty-fifth month. This procedure of rolling regressions with a fixed window of twenty-four months was used to cover the whole data sample. Finally, we tested the averages of these $T$ estimates to see if: $E\left(\gamma_{0}\right)=0$

(i.e. pricing errors are zero), $E\left(\gamma^{m}\right)>0$ and $E\left(\gamma^{f}\right)>0$ (i.e. a positive risk premium on the excess market return and other factors $f$ ). In Table 5 we report the average slopes and $t$-statistics (in parenthesis) from the month-by-month regressions of the excess stock returns on the betas of the excess market returns and the first three principal factors. ${ }^{*},{ }^{* *}$, and ${ }^{* * *}$ indicate a significant difference at the 10,5 , and 1 percent levels, respectively.

\begin{tabular}{|c|c|c|c|c|c|c|}
\hline $\begin{array}{l}\text { Countryl } \\
\text { Adj. } R^{2}\end{array}$ & Sample & $\begin{array}{c}\text { Excess } \\
\text { Market } \\
\text { Return } \\
\left(\gamma^{m}\right) \\
\end{array}$ & $\begin{array}{l}\text { Pc1 } \\
\left(\gamma^{2}\right)\end{array}$ & $\begin{array}{l}\text { Pc2 } \\
\left(\gamma^{3}\right)\end{array}$ & $\begin{array}{l}\text { Pc3 } \\
\left(\gamma^{4}\right)\end{array}$ & $\begin{array}{c}\text { Constant } \\
\left(\gamma_{0}\right)\end{array}$ \\
\hline $\begin{array}{l}\text { Czech Rep. } \\
(0.1380)\end{array}$ & $\begin{array}{l}\text { Jun } 92-\mathrm{Dec} 07 \\
\text { (4660 obs.) }\end{array}$ & $\begin{array}{c}0.0025 \\
(0.3007)\end{array}$ & $\begin{array}{c}0.1556 \\
(0.5982)\end{array}$ & $\begin{array}{l}-0.4919 \\
\left(-1.5475^{\star}\right)\end{array}$ & $\begin{array}{c}0.1262 \\
(0.5825)\end{array}$ & $\begin{array}{c}-0.0036 \\
(-0.5204)\end{array}$ \\
\hline $\begin{array}{l}\text { Hungary } \\
(0.2881)\end{array}$ & $\begin{array}{c}\text { Jun } 92-\mathrm{Dec} 07 \\
\text { (1151 obs.) }\end{array}$ & $\begin{array}{c}0.0143 \\
\left(1.6145^{\star}\right)\end{array}$ & $\begin{array}{c}-0.0961 \\
(-0.3263)\end{array}$ & $\begin{array}{l}-0.1590 \\
\left(-1.3168^{*}\right)\end{array}$ & $\begin{array}{c}0.2186 \\
\left(1.4278^{\star}\right)\end{array}$ & $\begin{array}{c}-0.0076 \\
(-1.2128)\end{array}$ \\
\hline $\begin{array}{l}\text { Poland } \\
(0.3564)\end{array}$ & $\begin{array}{l}\text { Jun } 92-\mathrm{Dec} 07 \\
\text { (2937 obs.) }\end{array}$ & $\begin{array}{c}0.0127 \\
\left(1.8266^{\star \star}\right)\end{array}$ & $\begin{array}{c}0.2290 \\
\left(1.3839^{*}\right)\end{array}$ & $\begin{array}{c}-0.2090 \\
\left(-1.6572^{\star *}\right)\end{array}$ & $\begin{array}{l}-0.2424 \\
\left(-2.2612^{\star \star}\right)\end{array}$ & $\begin{array}{c}-0.0089 \\
\left(-1.8761^{* *}\right)\end{array}$ \\
\hline $\begin{array}{l}\text { Slovak Rep. } \\
(0.0365)\end{array}$ & $\begin{array}{c}\text { Feb } 96-\text { Oct } 03 \\
\text { (1348 obs.) }\end{array}$ & $\begin{array}{c}0.0092 \\
(0.6514)\end{array}$ & $\begin{array}{c}-0.4116 \\
(-0.9029)\end{array}$ & $\begin{array}{c}-0.3366 \\
(-0.9837)\end{array}$ & $\begin{array}{c}0.0182 \\
(0.0464)\end{array}$ & $\begin{array}{c}-0.0095 \\
(-0.7632)\end{array}$ \\
\hline
\end{tabular}




\section{Table 6 Results: GMM}

We estimated the GMM system, in which moment restrictions allowed for joint estimation of betas and gammas, as specified in the FMB procedure. Based on Cochrane (2005) we wrote the moment conditions in the following way:

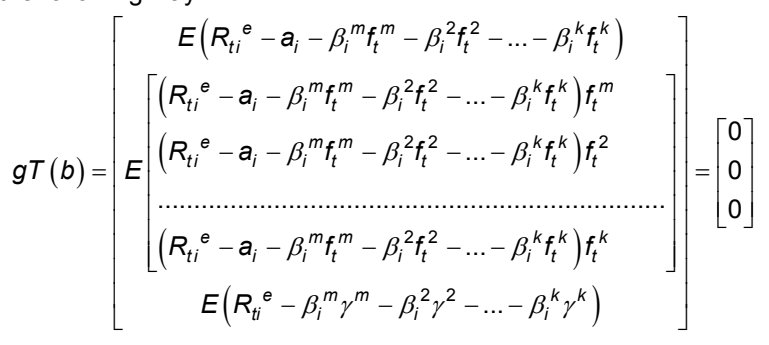

where $R_{t i}{ }^{e}$ is the $i$-th stock excess return (the $i$-th stock return minus the risk-free rate), $f_{t}^{m}$ is the local index excess return (the local index return minus the risk-free rate), and $f_{t}^{k}$ is the $k$-th factor return $(k=2 \ldots 4)$.

In this system there are $N(1+K+1)$ moment conditions since for each asset $N$ we have one moment condition for the constant, $K$ moment conditions for the $K$ factors and one moment condition that allows us to estimate the gammas (the asset-pricing model condition). On the other hand, there are $N(1+K)+K$ parameters and hence we have $n-K$ overidentifying restrictions. They can be tested with a chi-square test (the J-test for overidentifying restrictions). We estimated this system by the GMM, in which the optimal weighting matrix was obtained in an iterative process by sequential updating of the coefficients. To test the overall model we calculated the $J$-statistic in the following way:

$T^{*} J=T^{*}\left[g_{T}(\hat{b})^{\prime} \hat{S}^{-1} g_{T}(\hat{b})\right]$, where $g_{T}(\hat{b})$ are the moment conditions evaluated at the estimated values of coefficients $\beta$ and $\gamma$, whereas $\hat{S}^{-1}$ is the inverse of the optimal weighting matrix (the variance-covariance matrix). This statistic follows an approximately $\chi^{2}$ distribution with degrees of freedom equal to the number of moment conditions minus the number of parameters. In our case the $\mathrm{J}$-statistic was equal to 17.4 , whereas the $\chi^{2}$ critical value at the 95 percent level of significance with 39 degrees of freedom was 18.5. Since the $J$-statistic was less than the appropriate critical value we could not reject the model. In Table 6 we report the average slopes and $t$-statistics (in parenthesis) from a one-step GMM estimation of the excess stock returns on the excess market returns, inflation, industrial production, and the term structure for Poland with a time span of January 1993 to February 2003. *, **, and ${ }^{* * *}$ indicate a significant difference at the 10,5 , and 1 percent levels, respectively.

\begin{tabular}{cccc}
\hline $\begin{array}{c}\text { Excess Market } \\
\text { Return } \\
\left(\gamma^{m}\right)\end{array}$ & $\begin{array}{c}\text { Inflation } \\
\left(\gamma^{2}\right)\end{array}$ & $\begin{array}{c}\text { Ind. Prod. } \\
\left(\gamma^{3}\right)\end{array}$ & $\begin{array}{c}\text { Term } \\
\text { Structure } \\
\left(\gamma^{4}\right)\end{array}$ \\
\hline-0.0935 & -0.0073 & -0.0400 & -0.0016 \\
$\left(-2.3566^{* *}\right)$ & $\left(-1.9595^{*}\right)$ & $\left(-1.8555^{*}\right)$ & $\left(-2.3029^{* *}\right)$ \\
\hline
\end{tabular}




\section{Conclusions}

Emerging market returns have been studied quite extensively in the last decade. However, it is not clear which model should be used to explain the returns in these markets and to estimate the cost of capital. The cost of capital is important information that is needed to evaluate investment opportunities as well as to assess the performance of managed portfolios. In the developed markets, the Capital Asset Pricing Model (CAPM) is most often used to estimate the cost of capital, even though its empirical record is quite poor. Factor models have been developed to overcome some of the CAPM's shortcomings, in particular the inability of the excess market return alone to explain the variance of average stock returns. Factor models extend the CAPM by adding additional factors to the excess market return in order to improve the predictive power of the model.

In this paper we tested various asset-pricing models and evaluated their relative performance in explaining average stock returns in the Visegrad countries. These models, as argued, can potentially be used to estimate the cost of capital, which is then used to evaluate investment opportunities. We began by formally estimating the CAPM by the Fama-MacBeth (FMB) procedure using data from the Visegrad markets to see how it performs. Having confirmed the low power of the CAPM in explaining the variance of average stock returns we then proceeded to estimate factor models. We employed a macroeconomic factor model based on the factors used by CRR (1986). In our baseline model we included the following four factors: excess market return, industrial production, inflation, and excess term structure. We estimated this four-factor model using the FMB procedure. This model holds in all the Visegrad countries, as the null hypothesis $\left(H_{0}: E\left(\gamma_{0}\right)=0\right)$ could not be rejected. We performed tests of the added explanatory power between the CAPM (restricted model) and the baseline four-factor model (unrestricted model). In all countries we were able to reject the CAPM in favor of the baseline four-factor model. ${ }^{25}$

We also estimated alternative macroeconomic factor models. While more of the factors were statistically significant in these models, they could be rejected in favor of the baseline four-factor models in tests of added explanatory power for Hungary, Poland, and Slovakia. For the Czech Republic, an alternative four-factor model with industrial production, money, and exports turned out to be superior to the baseline four-factor model.

Even though these results turned out to be satisfactory, we decided to proceed with principal component analysis in order to extract the key factors that explain the variability of stock returns in these countries. In Poland the model was rejected, as the constant term was significant $\left(E\left(\gamma_{0}\right) \neq 0\right)$. For the other three Visegrad countries, the model could not be rejected and various principal factors turned out to be statistically significant (apart from Slovakia, where none of the factors was significant). In the Czech Republic, the second factor, summarizing the evolution of imports and exports, was statistically significant. In Hungary the excess market return was significant, along with the first and the second principal factors, driven mainly by changes in exchange rates, consumer prices, and primary commodity prices.

\footnotetext{
${ }^{25}$ In the Czech Republic, Hungary, and Poland we reject the CAPM in favor of the four-factor model at the 1 percent significance level, while in Slovakia we do so only at the 10 percent level.
} 
Based on these results we concluded that macroeconomic factor models, rather than the CAPM or the principal factor models, are suitable for estimating the cost of capital in Visegrad countries. Our conclusion is supported by the results obtained for Poland when using the one-step Generalized Method of Moments (GMM) estimation method. These alternative estimates, free of the errors-in-variables problem, resulted in all the factors turning significant, confirming that the Fama-MacBeth estimates are likely to be biased downward. Even though due to empirical problems we were not able to obtain similar alternative estimates for the other Visegrad countries we can expect that the estimates obtained by the FMB procedure most likely undermine the significance of macroeconomic factors in explaining the average stock returns.

\section{REFERENCES}

Bartholdy J, Peare P (2003): Unbiased Estimation of Expected Return Using CAPM. International Review of Financial Analysis, 12:69-81.

Bekaert G, Harvey C (1995): Time-Varying World Market Integration. Journal of Finance, 50:403-444.

Bekaert G, Harvey C (1997): Emerging Equity Market Volatility. Journal of Financial Economics, 43(1):29-77.

Bekaert G, Harvey C (2000): Foreign Speculators and Emerging Equity Markets. The Journal of Finance, 55:565-613.

Black F (1972): Capital Market Equilibrium with Restricted Borrowing. Journal of Business, 45: 444-455.

Black F, Jensen M, Scholes M (1972): The Capital-Asset Pricing Model: Some empirical tests. In: Jensen M (Ed.): Studies in the Theory of Capital Markets. Praeger Publishers Inc.

Brealey RA, Myers SC (1988): Principles of Corporate Finance. McGraw-Hill Book Company.

Breeden D (1979): An intertemporal asset pricing model with stochastic consumption and investment opportunities. Journal of Financial Economics, 7:265-296.

Campbell J (1996): Understanding risk and return. Journal of Political Economy, 104:298-345.

Chen N, Roll R, Ross SA (1986): Economic Forces and the Stock Market. Journal of Business, 59: 383-403.

Cochrane J (1996): A cross sectional test of an investment-based asset pricing model. Journal of Political Economy, 104:572-621.

Cochrane JH (2005): Asset Pricing. Princeton University Press: 241-242.

Cuthbertson K, Nitzsche D (2004): Quantitative Financial Economics : Stocks, Bonds and Foreign Exchange. John Wiley \& Sons Ltd.

Davidson R, MacKinnon JG (1993): Estimation and Inference in Econometrics. Oxford University Press.

Erb C, Harvey C, Viskanta T (1995): Country Risk and Global Equity Selection. Journal of Portfolio Management, Winter:74-83.

Erb C, Harvey C, Viskanta T (1996): Expected Returns and Volatility in 135 Countries. Journal of Portfolio Management, Spring:46-58.

Fama EF, French KR (1993): Common Risk Factors in the Returns on Stocks and Bonds. Journal of Financial Economics, 33:3-56.

Fama EF, French KR (1996): Multifactor explanations of asset pricing anomalies, Journal of Finance, 51:55-84. 
Fama EF, French KR (1988): Dividend yields and expected stock returns. Journal of Financial Economics, 22:3-25.

Fama EF, French KR (2004): The CAPM: Theory and Evidence. Journal of Economic Perspectives, 18:25-46.

Fama EF, MacBeth JD (1973): Risk, Return, and Equilibrium: Empirical Tests. Journal of Political Economy, 81:607-636.

Graham JR, Harvey CR (2001): The Theory and Practice of Corporate Finance: Evidence from the Field. Journal of Financial Economics, 60:187-243.

Harvey CR (1995): Predictable Risk and Returns in Emerging Markets. The Review of Financial Studies, 8(3):773-816.

Jagannathan R, Wang Z (1996): The conditional CAPM and the cross-section of expected returns. Journal of Finance, 51:3-53.

Jagannathan R, Wang Z (1998): Asymptotic Theory for Estimating Beta Pricing Models Using Cross-Sectional Regressions. Journal of Finance, 53:1285-1309.

Jagannathan R, Wang Z (2005): Consumption risk and the cost of equity capital. NBER Working Paper, no. 11026.

Jong F de, Roon FA de (2001): Time-Varying Market Integration and Expected Returns in Emerging Markets. CentER Discussion Paper, no 78.

Koulafetis P, Levis M (2002): The Fama-MacBeth Methodology versus the Non-Linear Unrelated Regression and Different Portfolio Formation Criteria. EFMA 2002 London Meetings.

http://ssrn.com/abstract=314383

Lakonishok J, Shapiro A (1986): Systematic Risk, Total Risk, and Size as Determinants of Stock Market Returns. Journal of Banking and Finance, 10:115-132.

Leledakis G, Davidson I, Karathanassis G (2003): Cross-sectional Estimation of Stock Returns in Small Markets: The Case of the Athens Stock Exchange. Applied Financial Economics, 13:413-426.

Lettau M, Ludvigson S (2001): Resurrecting the (C)CAPM: A crosssectional test when risk premia are time-varying. Journal of Political Economy, 109:1238-1287.

Lewellen J, Nagel S (2006): The Conditional CAPM Does Not Explain Asset-Pricing Anomalies. Journal of Financial Economics, 82(2):289-314.

Lewellen J, Nagel S, Shanken J (2006): A Skeptical Appraisal of Asset-Pricing Tests. NBER Working Paper, no. 12360.

Liew J, Vassalou M (2000): Can book-to-market, size, and momentum be risk factors that predict economic growth? Journal of Financial Economics, 57:221-245.

Lintner J (1965): The Valuation of Risky Assets and the Selection of Risky Investments in Stock Portfolios and Capital Budgets, Review of Economics and Statistics, 47:13-37.

Low C, Nayak S (2005): The Non-Relevance of the Elusive Holy Grail of Asset Pricing Tests: the 'True' Market Portfolio Doesn't Really Matter". EFA 2005 Moscow Meetings Paper.

http://ssrn.com/abstract=675423

Parker J, Julliard C (2005): Consumption risk and the crosssection of expected returns. Journal of Political Economy, 113:185-222.

Petkova R (2006): Do the Fama-French factors proxy for innovations in predictive variables? Journal of Finance, 61:581-612.

Piazzesi M, Schneider M, Tuzel S (2007): Housing, consumption, and asset pricing. Journal of Financial Economics, 83:531-569.

Reinganum M (1981): Misspecification of Capital Asset Pricing: Empirical anomalies. Journal of Financial Economics, 9:19-46.

Rouwenhorst KG (1999): Local returns factors and turnover in emerging stock markets. Journal of Finance, 54(4):1439-1464. 
Roll R (1977): A Critique of the Asset Pricing Theory's Tests. Journal of Financial Economics, 4(2):129-176.

Shanken J (1985): Multivariate Tests of the Zero-Beta CAPM. Journal of Financial Economics, $14: 327-348$

Shanken J (1992): On the Estimation of Beta-Pricing Models. Review of Financial Studies, 5:1-34.

Sharpe W (1964): Capital Asset Prices: A Theory of Market Equilibrium Under Conditions of Risk. The Journal of Finance, 19:425-442.

Skoulakis G (2005): Assessment of Asset-Pricing Models using Cross-Sectional Regressions. Working paper, Northwestern University.

Sokalska M (2001): What Drives Equity Returns in Central and Eastern Europe. In: EFA 2002 Berlin Meetings Presented Paper. Warsaw School of Economics, Institute of Econometrics.

Stock J, Watson M (1998): Diffusion Indexes. NBER Working Paper, no. 6702

Vassalou M (2003): News related to future GDP growth as a risk factor in equity returns. Journal of Financial Economics, 68:47-73.

Yogo M (2006): A consumption-based explanation of expected stock returns. Journal of Finance, 61:539-580.

Wang Y (2005): A comparison of factor models for explaining the cross section of stock returns. Working paper, Kellogg School of Management. 